\title{
SENSORIAMENTO REMOTO E SIG NA IDENTIFICAÇÃO DE ÁREAS PROPENSAS À FORMAÇÃO DE FAVELAS: O CASO DE MONTES CLAROS (MG)
}

\author{
REMOTE SENSING AND GIS TO IDENTIFY AREAS AT RISK OF SLUM \\ FORMATION IN CITY MEDIUM: THE CASE OF MONTES CLAROS (MG)
}

\section{TELEDETECCIÓN Y SIG EN LA IDENTIFICACIÓN DE LAS ZONAS PROPENSAS A FORMACIÓN DE FAVELA: EL CASO DE MONTES CLAROS (MG)}

\author{
Marcos Esdras Leite - Universidade Estadual de Montes Claros - Montes Claros - Minas Gerais - Brasil \\ marcosesdras@ig.com.br
}

Jorge Luis Silva Brito - Universidade Federal de Uberlândia - Uberlândia - Minas Gerais - Brasil

jbrito@ufu.br

\section{Resumo}

As cidades médias destacam-se como polo convergente de imigrantes, por apresentarem características importantes na atração populacional. Essa situação faz com que a demanda de moradia seja incompatível com a oferta, o que força a população de menor renda a ocupar espaços de maneira ilegal. Esse cenário descreve a realidade da cidade de Montes Claros, uma vez que ela se destaca como polo de uma vasta região que abrange todo o norte de Minas Gerais. Como consequência desse cenário, a cidade se expandiu sem um controle efetivo do poder público municipal e invasões para fins de moradia ocorreram. Diante dessa realidade, este trabalho analisou, por meio do sensoriamento remoto e do Sistema de Informações Geográficas (SIG), alguns atributos espaciais que se repetiram nas favelas da cidade de Montes Claros e classificou as áreas públicas com risco de formação de favelas. 0 uso das geotecnologias, notadamente 0 sensoriamento remoto, com imagens de alta resolução espacial, e do SIG permitiram identificar as áreas públicas vagas na cidade de Montes Claros e associar-Ihes variáveis que potencializam a invasão desses imóveis, como 0 valor comercial do terreno, a distância do centro, a proximidade de favelas, a infraestrutura básica e a proximidade de cursos de água. Essa metodologia evidenciou a concentração de imóveis públicos vazios nas áreas mais pobres da cidade, tornandoas propensas à formação de favelas.

Palavras-chave: sensoriamento remoto, SIG, favela, cidade média, Montes Claros.

\section{Abstract}

Medium cities stand out as convergent pole of immigrants, because they have important features in attracting population. This situation means that the demand for housing is incompatible with supply, this forces the low income population to occupy spaces illegally. This scenario describes the reality of the city of Montes Claros, since it stands as a pole of a vast region that encompasses the whole North of Minas Gerais. As a consequence of this scenario, the city has expanded without an effective control of municipal government and encroachments for housing purposes occurred. Given this fact, this study examined, through remote sensing and Geographic Information System (GIS), some spatial attributes that were repeated in the slums of the city of Montes Claros and ranked the public areas at risk of slum formation. The use of geo-technology, especially remote sensing, images with high spatial resolution, and the GIS to light the public areas and places in the city of Montes Claros and associate with these variables that enhance the invasion of these properties and the consequent formation slum. This methodology showed the concentration of empty public buildings in the poorer areas of cities, making it prone to slum formation in these lands.

Keywords: remote sensing, GIS, slum, city medium, Montes Claros. 


\section{Resumen}

Las ciudades medianas se destacan como polo de convergencia de los inmigrantes, porque tienen características importantes en la atracción de población. Esta situación significa que la demanda de viviendas es incompatible con la oferta, esto obliga a la población de bajos ingresos a ocupar espacios de manera ilegal. Este escenario describe la realidad de la ciudad de Montes Claros, ya que se erige como un polo de una vasta región que abarca todo el norte de Minas Gerais. Como consecuencia de este escenario, la ciudad se ha expandido sin un control efectivo del gobierno municipal y las invasiones con fines de vivienda se produjo. Teniendo en cuenta este hecho, este estudio examina, a través de la teledetección y los Sistema de Información Geográfica (SIG), algunos atributos espaciales que se repitieron en los barrios pobres de la ciudad de Montes Claros y calificadas las zonas públicas corren el riesgo de formación de barrios marginales. El uso de la geo-tecnología, especialmente la teledetección, las imágenes con alta resolución espacial, y el SIG, a la luz los espacios públicos y lugares de la ciudad de Montes Claros y asociarse con estas variables que mejoran la invasión de estas propiedades y la consecuente formación los barrios de tugurios. Esta metodología mostró la concentración de edificios públicos vacíos en las zonas más pobres de las ciudades, por lo que es propensa a la formación de barrios marginales en estas tierras. Palabras clave: teledetección, SIG, favela, ciudade mediana, Montes Claros.

\section{Introdução}

Analisando a distribuição espacial e temporal das favelas, bem como a propriedade do terreno, constatou-se que existem variáveis que potencializam a possibilidade de uma área ser invadida e, consequentemente, dar origem a uma favela. Neste sentido, o processo de formação de favela apresenta alguns aspectos comuns, que podem ser usados como elementos indicadores para essa formação.

É importante ressaltar que esta proposta não se configura como previsão de formação de favelas, pois estas são um fenômeno social e, como tal, sua previsão é complexa e envolve a possibilidade de vários cenários. Com isso, o objetivo deste artigo é analisar, por meio do sensoriamento remoto e do Sistema de Informações Geográficas (SIG), os atributos espaciais que se repetiram nas favelas da cidade de Montes Claros (MG): o valor comercial do terreno, a distância do centro, a proximidade entre as favelas e estas dos cursos de água, e a infraestrutura básica. Além disso, busca também apontar os espaços vulneráveis à formação de favela. O resultado pode ser usado pelo agente tomador de decisão e, assim, auxiliar na gestão do uso do solo. Esta contribuição é importante, haja vista que a ocupação ilegal do solo urbano ocorre de maneira rápida, logo, o monitoramento antecipado e direcionado para algumas áreas aumenta a possibilidade de eficiência da gestão urbana.

A partir dessa necessidade, os estudos sobre os assentamentos urbanos ilegais em cidades médias são relevantes, pois produzem novos 
conhecimentos sobre a questão da moradia, além de propor novas metodologias. No estudo da ocupação informal urbana, cujo objetivo é auxiliar na gestão dessas cidades, o uso das geotecnologias surge como instrumento com grande potencial de aplicação nas atividades de gestão urbana.

O emprego das geotecnologias para o estudo específico dos assentamentos urbanos informais ainda é muito complexo, pois trata-se de áreas que, na maioria dos casos, são excluídas de políticas públicas, porque, como não são legalizadas, não pagam impostos. Esse fator faz com que os dados sobre as favelas e loteamentos clandestinos sejam escassos, ou mesmo inexistentes. Com essa falta de dados, a proposição e a implantação de ações tornam-se muito difíceis, principalmente diante da burocracia do poder público em aprovar planos para uma área cujas informações sobre a população beneficiada são escassas.

O tamanho das casas e da área, a forma das ocupações e mesmo a topografia do relevo dos assentamentos urbanos informais são complicadores para a coleta de dados. As geotecnologias, precisamente o sensoriamento remoto, são uma alternativa para reduzir esses obstáculos, haja vista que, com a imagem de alta resolução, podem-se obter dados sobre os aglomerados urbanos de baixa renda, inclusive de uma favela.

Apesar das vantagens fornecidas pelo sensoriamento para a coleta de dados em área de baixa renda, há algumas dificuldades que não são solucionadas pelas tecnologias. A resposta espectral dos alvos nessas áreas é outro complicador, pois no espaço intraurbano há uma variedade de curvas espectrais de diversos alvos que, dada a sua semelhança espectral e aos problemas mencionados anteriormente, torna ainda mais difícil o trabalho de discriminar alvos desse espaço (Estevam, 2006).

Embora existam essas dificuldades, as geotecnologias apresentaram êxitos nos resultados de vários trabalhos. No estudo de Ishikawa (2001), por exemplo, foi apresentada a potencialidade das imagens Ikonos para áreas urbanas, principalmente na identificação de novas edificações. Matias e Nascimento (2006), por sua vez, aplicando as geotecnologias no mapeamento das áreas de ocupação irregular na cidade de Ponta Grossa (PR), conseguiram localizar e quantificar as áreas em que a ocupação não respeitava a lei de parcelamento do solo e a legislação ambiental.

Tomando como referência esses trabalhos de aplicação das geotecnologias, pode-se afirmar que para o levantamento e identificação dos ele- 
mentos potencializadores da formação de favelas é importante conhecer as características da cidade a ser analisada.

\section{A cidade de Montes Claros}

Para pensar a formação de favelas, há que se conjugar as características do terreno com as da cidade. Assim, as informações socioeconômicas da cidade de Montes Claros mostram suas peculiaridades como polo de uma vasta região de baixo dinamismo econômico. A Figura 1 mostra a localização de Montes Claros no norte de Minas Gerais. A região destaca-se por apresentar, com o Vale do Jequitinhonha e o Mucuri, os piores indicadores sociais do estado e um baixo dinamismo econômico, o que reforça a polarização regional de Montes Claros.

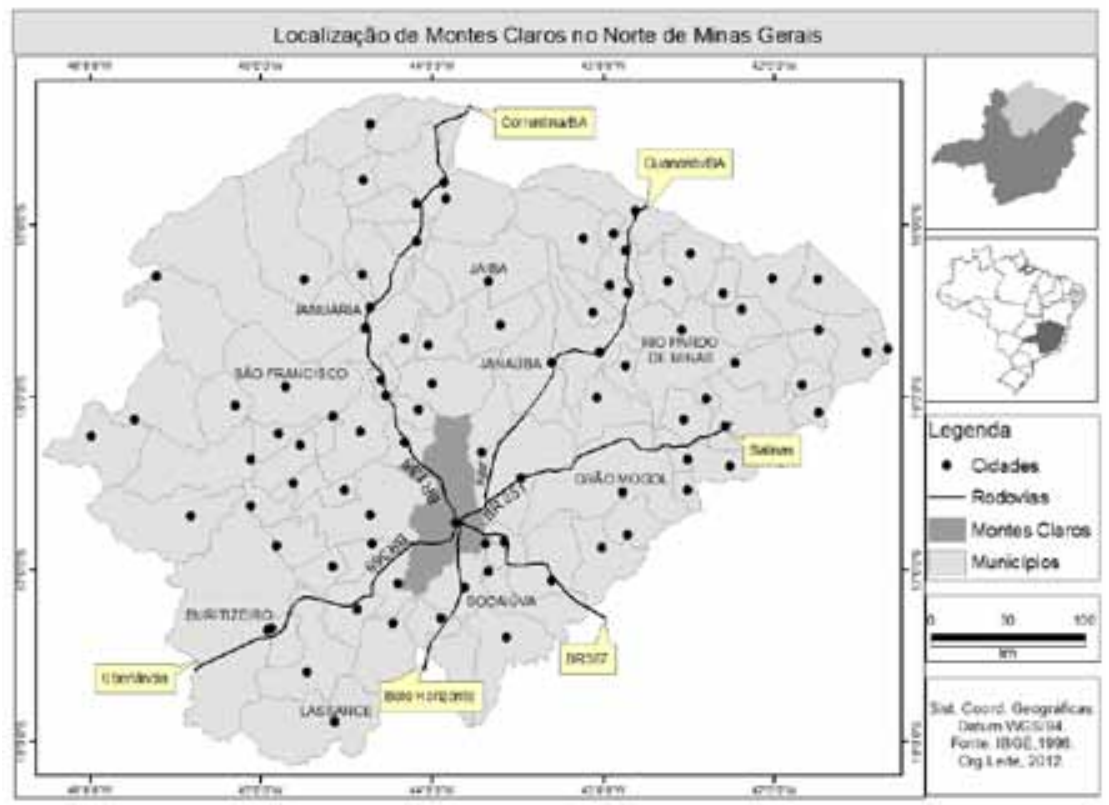

FIGURA 1 - Localização do município de Montes Claros no norte de Minas Gerais Fonte: IBGE (1996). 
A posição de centro econômico faz com que a população desse município tenha crescimento populacional maior do que a média nacional. De acordo com o Atlas de Desenvolvimento Humano no Brasil (2003), no período de 1991 a 2000, a população de Montes Claros teve uma taxa média de crescimento anual de 2,39\%, passando de 250.062 em 1991 para 306.947 em 2000. Esse aumento foi maior do que a taxa média do Brasil e de Minas Gerais, que apresentaram, no mesmo período, um crescimento de $1,64 \%$ e $1,44 \%$, respectivamente.

A migração intensa para Montes Claros desde a década de 1970 provoca a expansão rápida do espaço urbano, e, por isso, o governo local tem dificuldade em planejar uma política habitacional para incluir as famílias migrantes. Esse deslocamento para a cidade aumenta a demanda por terra pela população de baixa renda, o que gera ocupação ilegal de parcela significativa do espaço urbano. Além disso, há espaço disponível para expansão horizontal urbana na periferia, sem acesso à infraestrutura. Esses novos citadinos, em geral, apresentam pequena qualificação profissional e baixa renda, o que dificulta o acesso à moradia legal. Nesse contexto, proliferam nas cidades médias as invasões de terra e a formação de favelas.

Leite (2011) encontrou 21 favelas na cidade de Montes Claros, número maior que o do IBGE, que classifica 17 áreas como aglomerados subnormais, isto é, favelas e assemelhados, como exposto na Figura 2. Essa diferença está relacionada à atualização dos dados do IBGE, uma vez que essas informações são de 2000, enquanto Leite (2011) adotou como base as informações de 2005 e 2009. Por isso, os dados do autor supracitado estão mais atuais.

A análise da distribuição espacial das favelas na pesquisa de Leite (2011) revelou que há predomínio desses assentamentos humanos nas margens dos cursos da água da cidade. Além disso, a maior parte das favelas surgiu em terrenos públicos, sobretudo, nos municipais, definidos como áreas institucionais. 


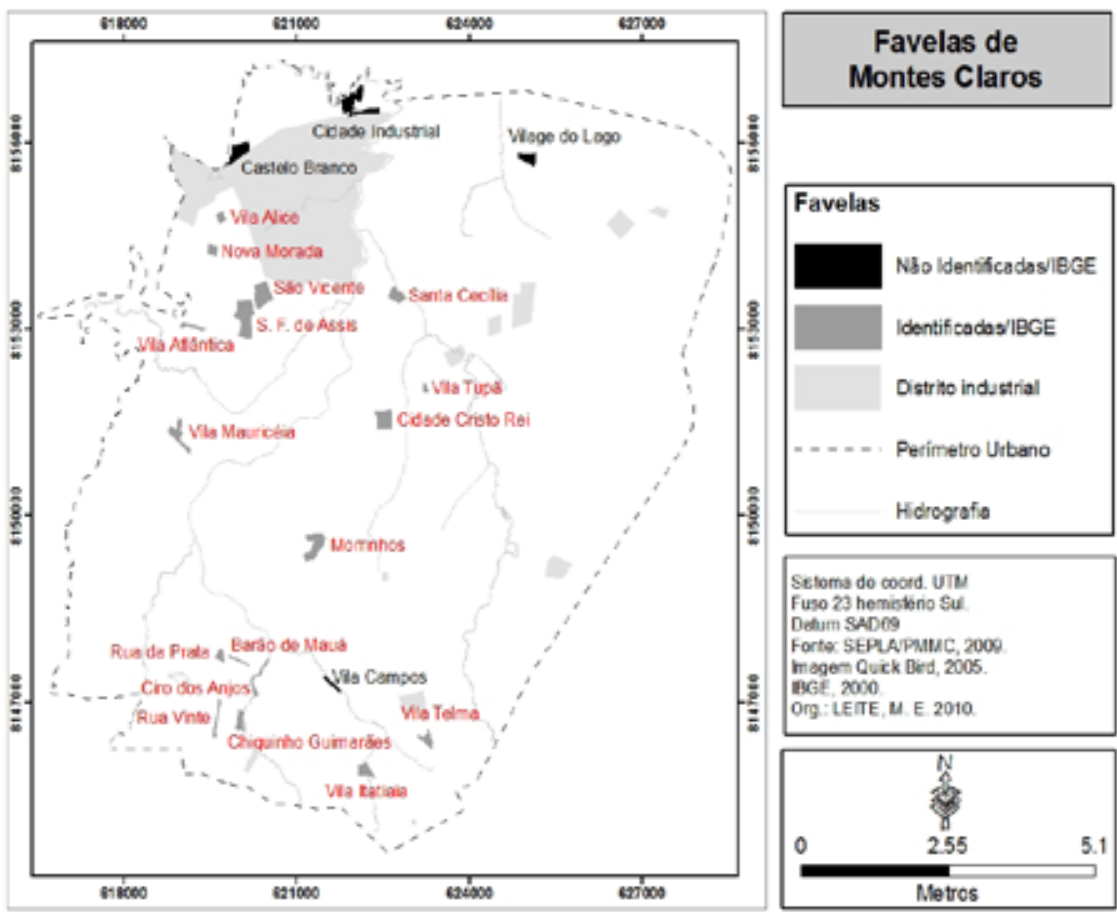

FIGURA 2 - Favelas de Montes Claros (MG) Fonte: SEPLA/PMMC (2009), IBGE (2000).

\section{Procedimentos metodológicos}

Subsidiado pelas análises realizadas por Leite (2011), que mostrou que a maior parte das favelas na cidade de Montes Claros está localizada em terrenos públicos municipais, buscou-se nesta pesquisa, no cadastro técnico imobiliário da Secretaria de Planejamento Municipal, a localização dos terrenos urbanos pertencentes à Prefeitura Municipal de Montes Claros que permanecem desocupados. Em seguida, esses dados foram vetorizados no software Arc Gis 9.3, tendo como base as plantas dos loteamentos e a imagem do satélite Quick Bird. Essa imagem possui quatro bandas espectrais, sendo que uma dessas está no pancromático, com resolução espacial de 0,61 metros, e as outras três estão compreendidas na faixa multiespectral (RGB), com resolução espacial de 2,4 metros. Dessa forma foi possível fazer uma composição colorida em cor verdadeira, na 
qual a de melhor resposta foi a combinação 1r2g3b. Com essa composição, os processos de fotointerpretação e de classificação foram facilitados.

Com o uso da composição colorida, a imagem apresentou uma resolução espacial de 2,4 metros. Para melhorar essa resolução espacial da imagem multiespectral foi aplicada a técnica de fusão. Essa técnica é comumente usada no trabalho de processamento digital de imagens, pois gera novas imagens que combinam as vantagens das imagens usadas, e com isso preserva-se a informação espectral (quantidades de bandas) com a melhor informação espacial.

Após serem gerados os polígonos dos terrenos públicos municipais vagos, foi criado o banco de dados. Para classificar as áreas com potencial para formação de favelas foram definidas algumas variáveis, tendo como base o levantamento bibliográfico e a análise das favelas existentes em Montes Claros. Em outros trabalhos sobre favelas, como os de Carvalho (2001), Bueno et al. (2004), Costa (2004) e Estevam (2006), constatou-se que algumas características são mais recorrentes que outras na área em que a favela se formou. Isso foi percebido nas favelas da cidade estudada neste trabalho.

Em Montes Claros, a característica primordial das áreas em que as favelas se formam foi a propriedade pública do terreno, por isso, este estudo considerou apenas as áreas públicas municipais vagas. Com isso, as outras variáveis selecionadas foram:

a) valor comercial do terreno, pois a área de menor valor é mais vulnerável à ocupação ilegal;

b) distância do centro, item que influencia diretamente no valor do solo urbano e na pressão para ocupação formal;

c) proximidade de favelas, haja vista que existe uma migração entre pessoas que moram em favelas antigas para as de ocupação recente;

d) infraestrutura básica, porque as áreas ocupadas ilegalmente normalmente não possuem nenhum tipo de infraestrutura no início da ocupação e isso interfere no valor do solo;

e) proximidade de cursos de água, pois na cidade estudada a maior parte das favelas existentes está localizada nas margens dos córregos, que se encontram poluídos por esgoto residencial.

Com isso, as áreas públicas vagas foram analisadas e as variáveis sobrepostas, tendo como resultado a hierarquização das áreas com maior incidência de elementos que potencializam a formação de favelas. A 
legenda dessa classificação, exposta na Figura 3, foi composta por cinco classes, sendo que estas foram associadas à quantidade de variáveis identificadas nas áreas vagas, conforme o Quadro 1.

QUADRO 1 - Descrição das classes de risco de formação de favelas

\begin{tabular}{|l|l|}
\hline Classe & Critério \\
\hline Muito alto & Ocorrência entre 4 e 5 variáveis \\
\hline Alto & Ocorrência de 3 variáveis \\
\hline Moderado & Ocorrência de 2 variáveis \\
\hline Baixo & Ocorrência de 1 variável \\
\hline Muito baixo & Ocorrência de nenhuma variável \\
\hline
\end{tabular}

Fonte: Organizado pelo autor Marcos Esdras Leite.

Com esse critério, as áreas que apresentaram mais características que potencializam a ocupação ilegal foram classificadas com o nível mais elevado de risco de formação de favela. Dessa maneira, à medida que a presença dessas características é menor no terreno analisado, o risco de formação de favela diminui, segundo a classificação adotada.

É importante destacar que esse resultado é um indicativo para a constituição de favelas, entretanto, como se trata de um processo social complexo e dinâmico, não há precisão na simulação de sua formação. Por isso, é importante o monitoramento constante das áreas vagas.

\section{Resultados e discussão}

Com a metodologia adotada, foi possível identificar as áreas com maior propensão ao surgimento de favelas. O sensoriamento remoto e o SIG permitiram visualizar todo o sistema urbano de Montes Claros, o que subsidiou a análise da organização espacial e social da cidade. Essas tecnologias contribuíram para integrar as variáveis consideradas, e com isso o resultado foi representado espacialmente.

A Figura 3 traz a classificação das áreas mais propensas à formação de favelas em Montes Claros, e nesse mapeamento constam todas as áreas vagas que pertencem ao município, embora a possibilidade de ocupação ilegal em algumas delas seja bastante remota, por tratar-se de espaços localizados em setores de valorização imobiliária, em que há interesse 


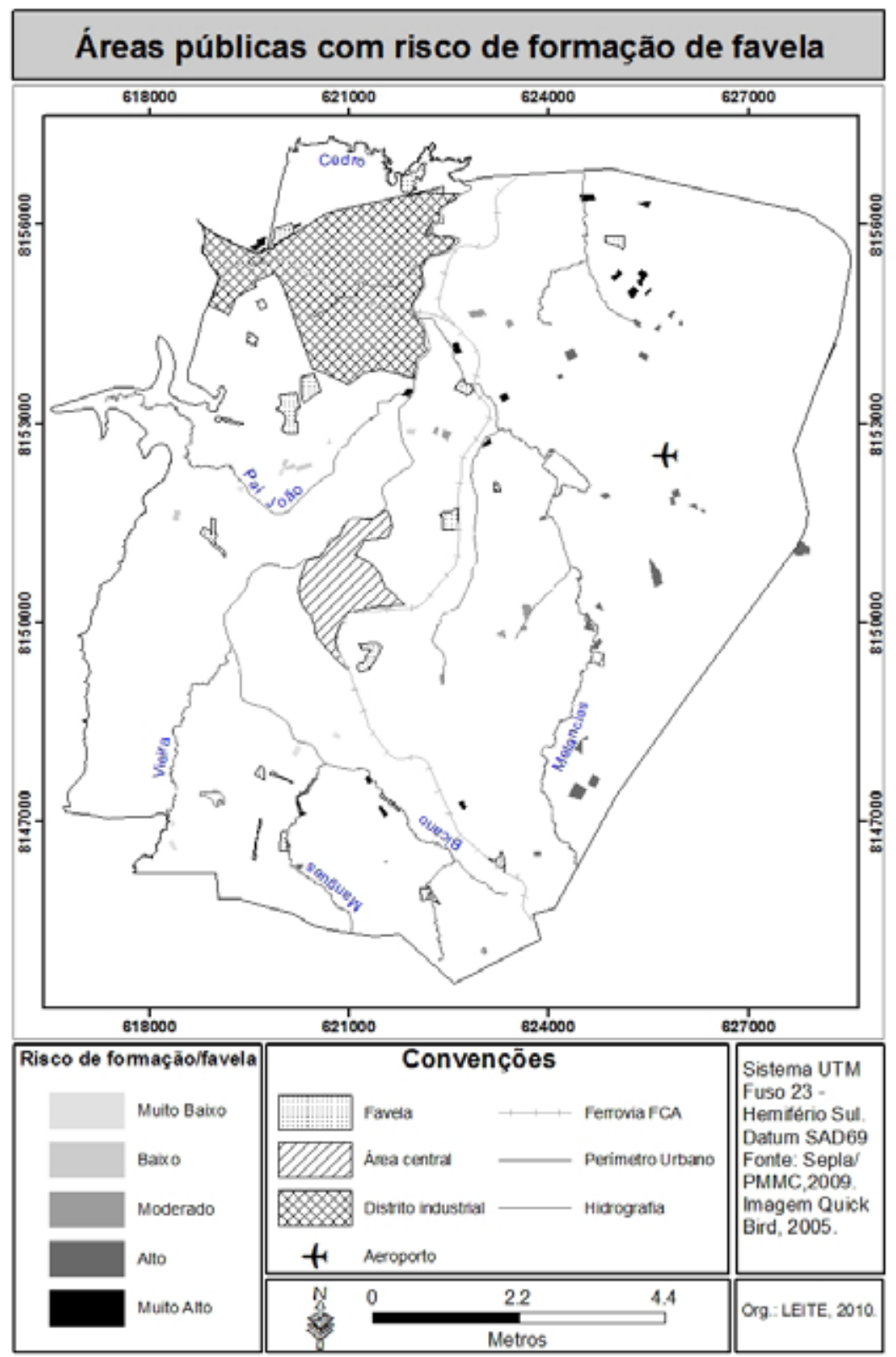

FIGURA 3 - Áreas públicas com risco de formação de favelas Fonte: SEPLA/PMMC, 2009; Imagem do satélite Quick Bird, 2005. 
econômico dos agentes formadores do espaço urbano. Antes de analisar a classificação de risco de formação de favelas nas áreas públicas que se encontram vagas na cidade de Montes Claros, é necessário discutir alguns pontos interessantes sobre a distribuição espacial desses terrenos.

Foram encontradas, neste trabalho, 82 áreas municipais que ainda não estão ocupadas e cuja distribuição está concentrada nas regiões norte e leste da cidade de Montes Claros, conforme mostra a Figura 3. Na região norte está o maior número de áreas públicas desocupadas, 39 áreas, enquanto na região leste existem 23 áreas. O total dessas duas regiões, 62 áreas, representa 65,6\% de todas as áreas públicas vazias do espaço urbano de Montes Claros.

Em relação às outras regiões da cidade, percebe-se que na parte central está a menor quantidade, pois foram identificadas apenas duas. A zona sul da cidade apresentou nove áreas, das quais seis estão próximas das margens dos cursos da água. Na região oeste foi encontrada a mesma quantidade constatada no sul da cidade.

Com base nessa análise, pode-se observar que as áreas de ocupação recente são as que apresentam o maior número de áreas públicas desocupadas. Essa situação é previsível, tendo em vista que as Leis Federais n. 6.766/79 e 9.785/99 (Brasil, 1979, 1999) dispõem que parte da área do loteamento seja destinada para fins de recreação, ou seja, parques, praças e áreas verdes, e para uso institucional. Dessa forma, é compreensível que nos loteamentos recentes haja áreas públicas que não estão ocupadas, pois ainda não houve tempo para a implantação dos equipamentos previstos.

O número de áreas públicas vazias nos loteamentos recentes de alta renda, entretanto, foi pequeno, apenas seis, que estão concentrados na região oeste da cidade de Montes Claros. Uma prática comum na administração municipal brasileira pode esclarecer esse fato: a doação de áreas para instituições públicas, organizações não governamentais e instituições filantrópicas. Mas um questionamento permanece: por que são doadas áreas em locais de grande valorização imobiliária, e não naquelas de baixo valor do imóvel? Além disso, no bairro Ibituruna, área de alta valorização imobiliária, não existem terrenos públicos municipais vagos, mesmo não havendo instalação de serviços públicos no setor.

A permuta e a comercialização são medidas legais que fazem com que os imóveis públicos, em áreas valorizadas da cidade, se tornem cada vez mais escassos. As Figuras 4 e 5 mostram a iniciativa da Prefeitura de comercializar áreas públicas para aumentar a receita municipal. 


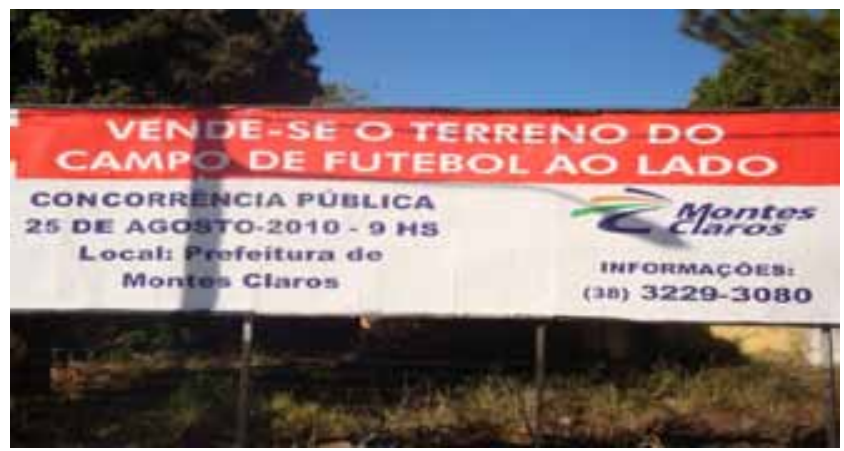

FIGURA 4 - Anúncio de leilão público para venda de terreno municipal Fonte: Acervo pessoal do autor Marcos Esdras Leite.

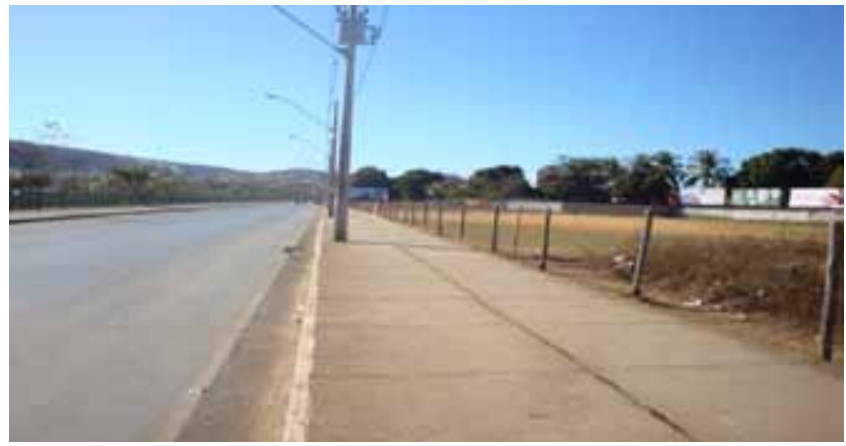

FIGURA 5 - Terreno público municipal anunciado na Figura 4 Fonte: Acervo pessoal do autor Marcos Esdras Leite.

Discutindo o enfoque deste trabalho, as favelas e as áreas propensas à formação desse tipo de moradia, constatou-se, a partir da Figura 3, que as áreas com risco Muito Alto e Alto de formação de favela apresentam um padrão de localização na periferia norte e leste da cidade. As áreas nessas classes predominaram e representaram $72 \%$ dos terrenos com potencial para formação de favela, sendo 24 áreas classificadas com risco Muito Alto e 35 com risco Alto.

Isso ocorre porque as partes norte e leste da cidade concentram fatores potencializadores para a ocupação ilegal de baixa renda. Destaca-se, nesse aspecto, a localização, que se caracteriza como o primeiro elemento a ser observado para a ocupação ilegal. Para Carvalho (2001), os terrenos distantes da parte mais aglomerada da cidade, como o centro comercial, 
por exemplo, têm preço mais baixo que em outras áreas da cidade e, por isso, são mais suscetíveis à provisão de moradia social.

No caso da cidade estudada, a parte norte está distante da área de alta valorização do solo, isto é, a zona sudoeste de Montes Claros, e próxima do distrito industrial, onde o preço da terra urbana é mais barato. Por isso, a parte norte da cidade atrai os migrantes de baixa renda. Outra variável presente nessa área e que desvaloriza os imóveis é a carência de infraestrutura. O índice de saneamento básico da região norte da cidade é de 70\%, um dos menores de Montes Claros. Soma-se a esses fatores de risco de formação de favela a presença de várias delas nessa parte da cidade. A proximidade de outras áreas de favelas é outro ponto importante a ser considerado, uma vez que, nas novas favelas, o número de moradores de outros assentamentos ilegais consolidados é considerável, como mostrou o estudo de Ribeiro e Lago (2001) sobre o perfil social da população residente em favelas na metrópole do Rio de Janeiro.

Como agravante para a formação de favelas na parte norte e leste de Montes Claros, está o fato de as áreas públicas presentes nesses setores da cidade estarem próximas das margens de cursos da água poluídos (Figura 6) ou em terrenos com declividade acentuada. Em alguns casos, estão dentro de voçorocas (Figura 7). Diante das características ambientais, Carvalho (2001) afirma que os terrenos que se encontram nessa situação ficam fora do mercado imobiliário legal, implicando o aumento da possibilidade de abrigar novas favelas. Nesse contexto, as áreas classificadas como de maior propensão à formação de favela concentraram-se nas regiões norte e leste da cidade, respectivamente.

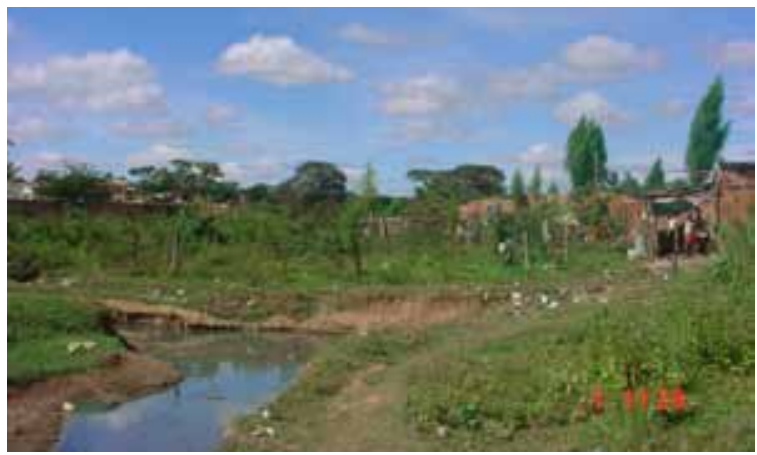

FIGURA 6 - Favela da Vila Campos, localizada na margem do rio Bicano Fonte: Acervo pessoal do autor Marcos Esdras Leite. 


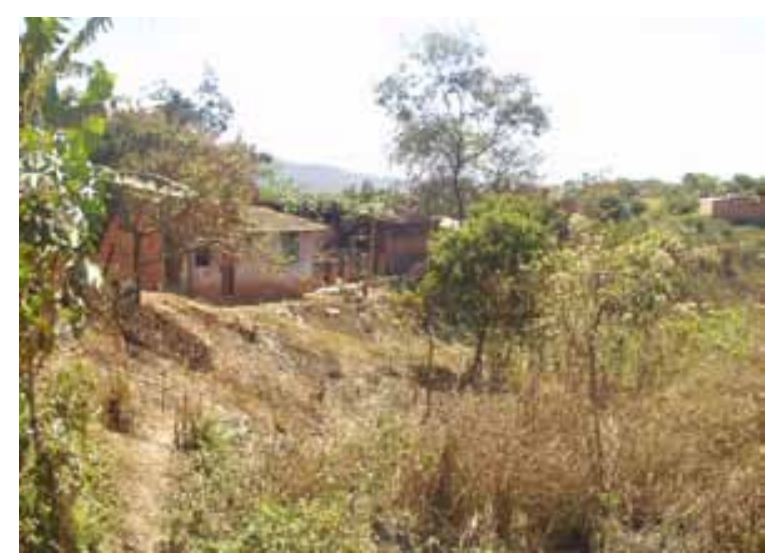

FIGURA 7 - Favela do Vilage do Lago, localizada em uma voçoroca Fonte: Acervo pessoal do autor Marcos Esdras Leite.

Desta forma, os elementos presentes em uma área pública vaga a tornam bastante vulnerável à ocupação pela população de baixa renda que está pressionada a obter uma alternativa de moradia. Neste sentido, a região norte apresentou uma concentração de áreas identificadas com risco Muito Alto e Alto para a formação de favelas, sendo classificadas nesses níveis 15 e 9 imóveis públicos, respectivamente.

O setor leste de Montes Claros apresentou 20 áreas públicas vagas, com risco Alto de formação de favela. Essa parte da cidade tem baixa taxa de ocupação do espaço, haja vista que é uma área de adensamento recente. Além disso, está no espaço descontínuo do tecido urbano, dificultando o acesso da sua população a todo o sistema urbano, o que provoca o agrupamento da população de baixa renda. Destacam-se nesse local os loteamentos irregulares, que possuem infraestrutura básica incompleta, como a falta da rede de esgoto. Essas características fazem com que essa região da cidade não desperte o interesse do mercado imobiliário. No entanto, por se tratar de uma área de ocupação recente, o setor leste não apresenta a variável proximidade de favelas existentes, por isso, suas áreas vagas foram classificadas com Alto risco de formação de favelas, haja vista que foram identificadas as outras quatro variáveis selecionadas para formação de favela.

Na parte sul foram formadas, na década de 1980, cinco favelas, influenciadas pela migração de pessoas de localidades próximas a essa 
parte da cidade. Entretanto, a partir desse período, a valorização imobiliária desse setor foi crescente, decorrente de investimentos públicos e privados, como a implantação de parques, shopping centers e loteamentos de alta renda. Isso reduziu a ocupação ilegal nessa área, principalmente na parte sudoeste, que é a mais valorizada. Essa situação explica como uma área com número elevado de favela apresenta apenas duas áreas classificadas com o nível Muito Alto de propensão à formação de favela. Além disso, essas áreas estão localizadas perto de rios que recebem esgoto doméstico.

Os imóveis públicos vagos da parte sul da cidade concentram-se nas margens dos córregos poluídos. Esses terrenos caracterizam-se pela falta de infraestrutura e pela proximidade de favelas implantadas na década de 1980. Por isso, o valor dos terrenos localizados na periferia sul é muito baixo em relação ao restante dos imóveis dessa parte da cidade.

As regiões central e oeste da cidade de Montes Claros tiveram a menor incidência de áreas com risco de serem ocupadas ilegalmente. São também as que apresentam o preço do solo urbano mais elevado, sendo a primeira comercial e a segunda, residencial de alta renda. Na classe Moderado (Figura 3), que de acordo com a metodologia são áreas que apresentam duas variáveis para formação de favelas, foram identificadas dez áreas. Os terrenos classificados localizam-se, em sua maior parte, na região pericentral de Montes Claros, em bairros de renda média. Entretanto, possuem duas variáveis para formação de favela, sendo elas a proximidade de favelas e a carência de infraestrutura. Na classe de risco Baixo de formação de favela foram identificados apenas sete imóveis, em sua maioria localizados na parte oeste da cidade, entre os setores de alta e de baixa renda.

A classe de risco Muito Baixo (Figura 3) contempla seis áreas, o que a torna a menor quanto à possibilidade de formação de favela. O risco é muito baixo porque essas áreas não apresentaram nenhuma variável de risco de formação de favelas, haja vista que estão dentro do setor de maior valorização imobiliária, ou seja, o sudoeste. Além disso, possuem infraestrutura básica completa e estão próximas do centro comercial da cidade.

Este resultado expõe a necessidade de monitoramento do espaço urbano, pois a falta de fiscalização e de aproveitamento das áreas públicas municipais as tornam vulneráveis à ocupação ilegal. Essa ocupação pode ser feita pela população de baixa renda, o que é o mais comum, ou 
mesmo pela de alta renda. Nesse contexto, as imagens de satélites permitem acompanhar as transformações nas cidades, e, com a oferta de imagens de alta resolução espacial, áreas mais complexas, como as favelas, podem ser mapeadas com maior precisão. Isso permite estudar as favelas com um nível de complexidade elevado, uma vez que o espaço interno dessas áreas é revelado pelas imagens de satélites.

\section{Considerações finais}

A cidade de Montes Claros apresenta crescimento demográfico acima da média nacional e do estado de Minas Gerais. Está localizada em uma região com baixo índice de desenvolvimento socioeconômico, na qual é o único polo regional. Além disso, seu solo urbano apresenta grande valorização, o que favorece a especulação imobiliária, tornando escasso o acesso de famílias de baixa renda à moradia. Essas características apontam para a possibilidade de crescimento das favelas existentes, bem como para a invasão de novas áreas.

Usando o sensoriamento remoto é possível monitorar a ocupação do espaço urbano e assim antever a invasão de novas áreas. Os dados extraídos do sensoriamento remoto, quando integrados ao banco de dados do SIG - que contemplam as variáveis de formação de favelas em áreas públicas aqui adotadas, como o valor comercial do terreno, a distância do centro, a proximidade de favelas, a infraestrutura básica e a proximidade de cursos de água -, mostraram ser eficazes, haja vista que permitem identificar as áreas que reúnem maior possibilidade de ser ocupadas ilegalmente.

As ocupações ilegais em Montes Claros, assim como na maioria das cidades brasileiras, surgem em imóveis públicos. Os dados deste artigo apontaram para uma concentração de áreas públicas na parte mais pobre da cidade estudada. Apenas esse fato merece atenção especial do poder público. Entretanto, quando se associam outras variáveis que potencializam a ocupação ilegal desses imóveis, provocando a formação de favela, nota-se que a parte norte de Montes Claros é a área com maior propensão a novas ocupações ilegais.

Diante do exposto, pode-se afirmar que as geotecnologias, principalmente o sensoriamento e o SIG, são técnicas importantes para monitorar e gerenciar a ocupação do solo urbano. Subsidiados pelas informações 
geradas por essas tecnologias, os gestores urbanos podem definir políticas públicas para o setor habitacional. Desta forma, espera-se atender a população de baixa renda com moradias que estão incluídas no sistema urbano, promovendo a inclusão social.

\section{Referências}

ATLAS DO DESENVOLVIMENTO HUMANO NO BRASIL. Rio de Janeiro: PNUD, IPEA, Fundação João Pinheiro, 2003.

BUENO, L. M. de M. et al. Moradia social em área de mananciais. São Paulo: Anablume, 2004.

BRASIL. Lei n. 6.766 de 19 de dezembro de 1979. Dispõe sobre o Parcelamento do Solo Urbano e dá outras providências. Disponível em: <http://www.lei.adv. br/6766-79.htm>. Acesso em: 20 dez. 2007.

BRASIL. Lei n. 9.785 de 29 de janeiro de 1999. Altera o Decreto-Lei n. 3.365, de 21 de junho de 1941 (desapropriação por utilidade pública) e as Leis n. 6.015, de 31 de dezembro de 1973 (registros públicos), e 6.766, de 19 de dezembro de 1979 (parcelamento do solo urbano). Disponível em: <http://www.lei.adv.br/ 9785-99. htm>. Acesso em: 24 abr. 2008.

CARVALHO, P. F. de. Problemas Ambientais na produção da cidade e da habitação de interesse social. In: CARVALHO, P. F. de; BRAGA, R. (Org.). Perspectivas de gestão ambiental em cidades médias. Rio Claro, SP: LPM-Unesp, 2001. p. 27-37.

COSTA, V. G. Favelas e assemelhados: o conceito e o estado da arte. Revista GeoUERJ, n. 15-16, p. 21-34, Rio de Janeiro, 2004.

ESTEVAM, E. A. Classificação de áreas de favelas a partir de imagens Ikonos: viabilidade de uso de uma abordagem orientada a objetos. 132 p. Dissertação (Mestrado em Ciências Cartográficas) - Faculdade de Ciências e Tecnologia, Unesp, Presidente Prudente, SP, 2006.

ISHIKAWA, M. I. Potencialidades de uso de imagens Ikonos/Geo para aplicações em áreas urbanas. 132 p. Dissertação (Mestrado em Ciências Cartográficas) Faculdade de Ciências e Tecnologia, Unesp, Presidente Prudente, SP, 2001.

LEITE, M. E. Geotecnologias aplicadas ao mapeamento do uso do solo urbano e da dinâmica de favela em cidade média: o caso de Montes Claros-MG. Tese (Doutorado em Geografia) - Instituto de Geografia, Universidade Federal de Uberlândia, Uberlândia, MG, 2011.

MATIAS, L. F.; NASCIMENTO, E. do. Geoprocessamento aplicado ao mapeamento das áreas de ocupação irregular na cidade de Ponta Grossa-PR. Revista Geografia, v. 31, n. 2, p. 317-330, Rio Claro, SP, 2006.

RIBEIRO, L. C. de Q.; LAGO, L. C. do. A oposição favela-bairro no espaço social do Rio de Janeiro. São Paulo em perspectiva, v. 15, n. 1, p.144-154, Seade, São Paulo, 2001. 
Marcos Esdras Leite - Doutor em Geografia pela Universidade Federal de Uberlândia - Professor da Universidade Estadual de Montes Claros, MG.

Jorge Luis Silva Brito - Doutor em Geografia pela Universidade de São Paulo - Professor da Universidade Federal de Uberlândia.

Recebido para publicação em abril de 2012

Aceito para publicação em agosto de 2012 